\title{
The missing intrauterine device
}

\author{
Rajesh Devassy $^{1}$, Sreelatha Gopalakrishnan ${ }^{2}$, Luz A. Torres-de la Roche ${ }^{3}$, \\ Hugo Verhoeven ${ }^{3}$, Maya S. De Wilde ${ }^{3}$, Rudy L. De Wilde ${ }^{3 *}$
}

\begin{abstract}
${ }^{1}$ Department of Advanced Laparoscopy Surgery, Dubai London Clinic and Specialty Hospital, Jumeirah, Dubai, UAE
${ }^{2}$ Department of Obstetrics and Gynaecology, Dubai London Specialty Hospital, Jumeirah, Dubai, UAE

${ }^{3}$ Department of Obstetrics and Gynaecology, University Hospital for Gynecology, Pius-Hospital, Oldenburg, Germany
\end{abstract}

Received: 09 August 2016

Accepted: 06 September 2016

\section{* Correspondence:}

Dr. Rudy Leon De Wilde,

E-mail: rudy-leon.dewilde@pius-hospital.de

Copyright: (c) the author(s), publisher and licensee Medip Academy. This is an open-access article distributed under the terms of the Creative Commons Attribution Non-Commercial License, which permits unrestricted non-commercial use, distribution, and reproduction in any medium, provided the original work is properly cited.

\begin{abstract}
The Intrauterine Contraceptive Device (IUD) is an acceptable and common form of contraception worldwide. The objective of this study was to report the case of an asymptomatic missing intrauterine contraceptive (IUD) inserted to prevent intrauterine adhesions after synechiolysis. A patient presented with missing IUD threads. Ultrasound of the pelvis showed an empty uterine cavity with the missing IUD probably anterior to the uterus. We present a stepwise approach in the management of the "lost IUD", where the strings of the device are not visible at the time of speculum examination. We suggest first determining sonographically whether the IUD is within the cavity. If it is in situ, options for retrieval are including hysteroscopic retrieval. If the IUD is not within the cavity, X-rays are recommended. The device will not be present on X-ray if expulsion has occurred. If the device is present on the Xray, cystoscopic or laparoscopic retrieval is required. IUD-providers should not only screen potential users and insert IUD correctly, but also ensure adequate follow-up with localization.
\end{abstract}

Keywords: IUD, Intrauterine device migration, Laparoscopy, Device removal

\section{INTRODUCTION}

The intrauterine contraceptive device (IUD) is an acceptable and common form of contraception worldwide. The percentages of women of reproductive age using IUD ranges between 5-40\%, excluding China. ${ }^{1}$ Complications associated with its use include missing or misplaced IUD's. The frequency of missing IUD's is less than $1 \% .^{2,3}$ Missing IUD's can be in the form of missing strings, spontaneous expulsion or perforation of the uterus (frank or occult). The IUD may migrate into the peritoneal cavity. Gut and bladder perforations have been reported following uterine perforations due to missing IUD's. 1,3

There are different diagnostic methods used in detecting missing IUD's. These include: pelvic examination with uterine sound, abdomino-pelvic ultrasound alone, abdomino-pelvic ultrasound combined with hysterosalpingography (HSG), plain abdominal X-rays, HSG, laparoscopy, minilaparotomy and laparotomy. Most patients with missing IUD's were reported after less than 6 user months with a peak within the first three months of IUD insertion., ${ }^{2,3}$

We report the case of an asymptomatic patient who had a missing IUD, found in an adhesion in between the bladder and uterus.

\section{CASE REPORT}

A 30 years old was referred to the outpatient department of obstetrics and gynaecology in Kenya, Nairobi (Kenyatta National Hospital) with a missing IUD inserted 
1 year ago. The patient had no complaints of pain, dysuria, abnormal vaginal discharge or gastrointestinal symptoms. She had not experienced hematemesis or melena. She had very scanty, period bleeding with irregular cycles. She was para 1: the last childbirth was by emergency Caesarea section because of fetal distress: Patient was discharged home after 4 days. Four weeks later, dilatation and curettage was done for retained placental tissue. In a month's time patient developed endometritis that was treated medically. An IUD was inserted in a peripheral clinic. She developed amenorrhea. Three months ago, she went to a gynecologist wanting to get pregnant; the missing IUD was noted.

Examination revealed an afebrile patient. A sonographic diagnosis of missing IUD with suspected Ashermann's syndrome was made. A pelvic ultrasound showed a normal sized uterus with a uniform echotexture of the myometrium. The endometrium was thin, measuring 3 $\mathrm{mm}$, with an empty uterine cavity. The echogenicity of the IUD could be seen in a position anterior to the uterus close to the urinary bladder. Both adnexa appeared normal. The complete blood counts, serum electrolyte, urea and creatinine, chest X-ray and electrocardiogram (ECG) were normal. She was prepared and planned for hysteroscopy and laparoscopy.

At surgical hysteroscopy, an intrauterine adhesiolysis in Ashermann's syndrome was done and the IUD was not located. Next cystoscopy was done without detection. At laparoscopy dense abdominal adhesions were lysed at the region anterior to the uterus. Intraoperative radiography (C - arm) was used to determine the exact position in relation to a uterine probe (Figure 1).

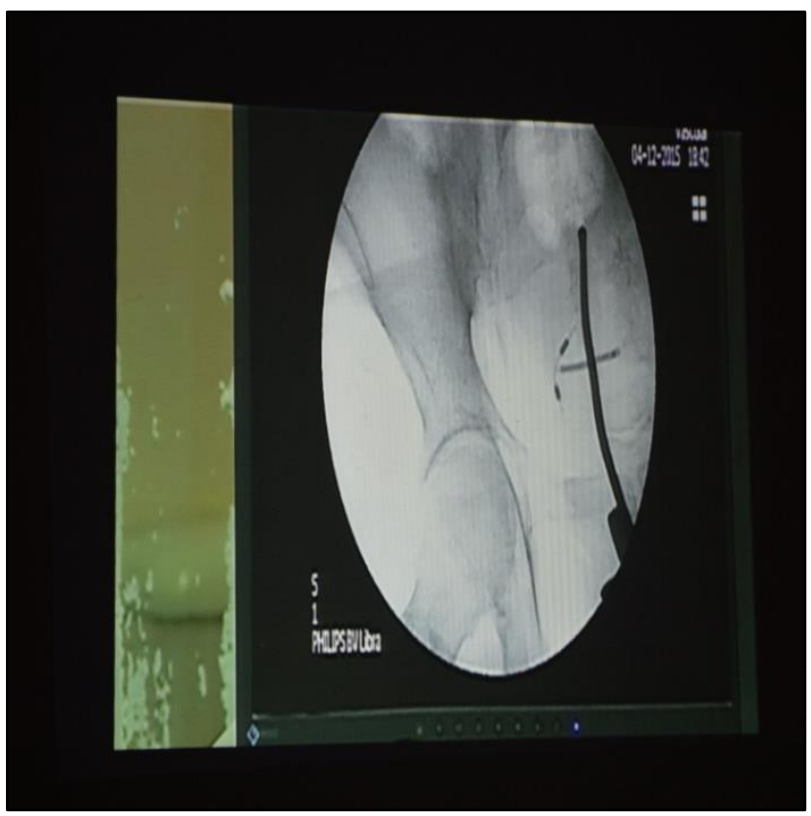

Figure 1: Intraoperative radiography showing the missing IUD in relation to the uterine probe.
Dissecting the area between the uterus and bladder, which was heavily fibrosed, exposed the embedded IUD and was extracted. The post-operative period was uneventful (Figure 2) (Figure 3).

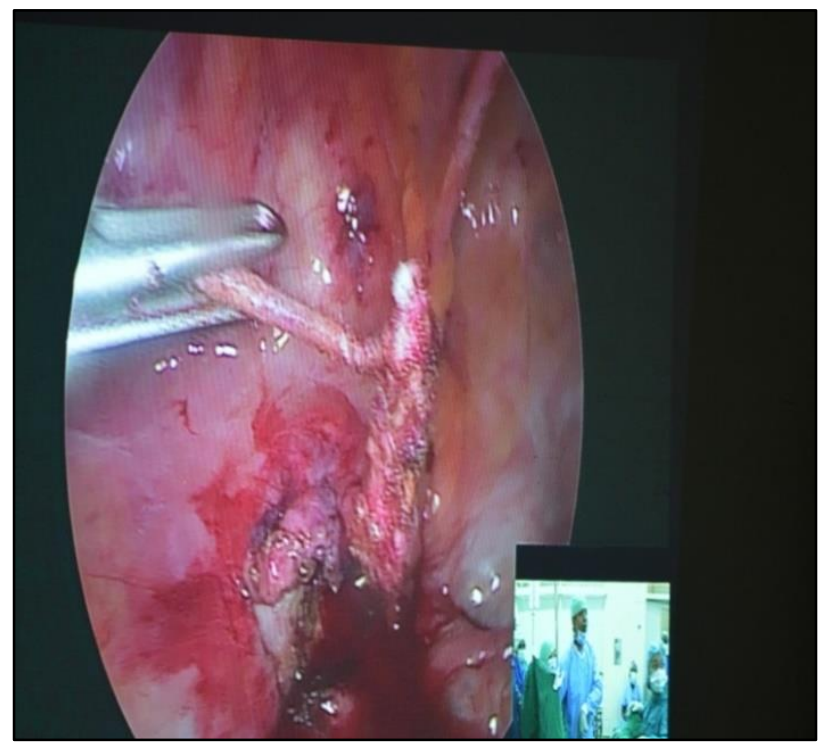

Figure 2: Dissection of the IUD out of the vesicouterine fold.

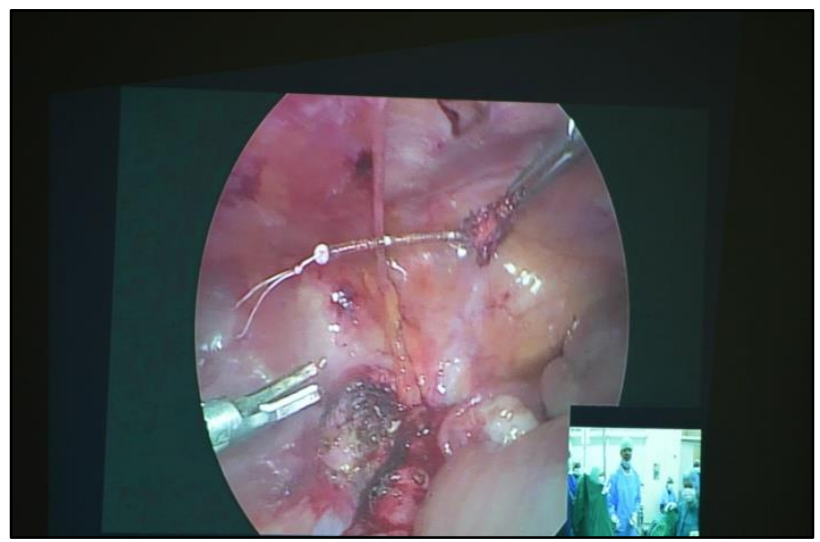

Figure 3: Subsequent extraction of the dislocated IUD out of the fibrosed vesicouterine excavation.

\section{DISCUSSION}

The intrauterine contraceptive device (IUD) is a widely accepted method of contraception. The percentage of women of reproductive age using IUD's ranges between $5-40 \%$ worldwide, excluding China. ${ }^{1}$ The prevalence rates of missing IUD's in most studies are between 0.5$2 \%$ of IUD-users. ${ }^{3}$ The proportion of missing IUD's is $0.25 \%$ of all IUD-users or $0.89 \%$ of new acceptors. 2 Missing IUD's with IUD-string not visible in the cervix may be as a result of expulsion or perforation of the uterus (frank or occult); sometimes it may be a result of migration into the peritoneal cavity. As reported in previous studies, it is important to realize that IUD's 
extremely rare perforate the uterus spontaneously; they normally do so at insertion. ${ }^{4}$

Cases have been reported of intraperitoneal IUD's presenting with abdominal pain, pregnancies, intraabdominal abscesses, urinary vesical stones, appendicitis and even ureteric obstruction leading to nephrectomy. ${ }^{5-7}$ However; it is rare to find it in perivesical adhesions as in this case. There are different ways of detecting peritoneal IUD's such as the use of abdominal ultrasound, transvaginal sonography, plain abdominal X-rays and laparoscopy. Sonogram is not as reliable if the IUD is surrounded by the Omentum or loops of bowel. ${ }^{8}$ In the presented case ultrasound identified the IUD but did not point out the exact location.

The most serious complication of IUD-use is uterine perforation, potentially causing severe morbidity. It has been suggested that a perforated IUD can be left in peritoneal cavity if it is made of non-irritating plastic. ${ }^{9}$ It has also been advised that all extra-uterine devices should be removed to discourage psychosomatic symptomatology commonly associated with forgotten devices. ${ }^{10}$ To prevent uterine perforation, the insertion of the IUD should be performed by an experienced gynecologist after a careful pelvic examination. Uterine size, consistency and position must be exactly known. ${ }^{8}$

To avoid complications, failure to locate the IUD-string in a patient who has not noticed expulsion, should be interpreted as a perforation or migration until proven otherwise. There should therefore be an effort to search for the missing IUD, including abdomino-pelvic ultrasound, trans-vaginal ultrasound and if inconclusive an abdominal X-ray (posterior-anterior and lateral view).In conclusion, IUD providers must screen potential users, insert the IUD correctly and ensure follow-up.
Funding: No funding sources Conflict of interest: None declared Ethical approval: Note required

\section{REFERENCES}

1. Centre for disease control. Intrauterine contraceptive devices. In family planning methods and practices in Africa. CDC Atlanta eds. $3^{\text {rd }}$ ed. Atlanta, Georgia; 1983.

2. Jimoh AAG, Balogun OR. Missing IUD strings: diagnosis and management at Ilorin. Nig J Med. 2004;13:118-23.

3. Lawal SO, Giwa-Osagie OF, Ogedengbe OK, Usifor CA. A review of IUCD related problems in Lagos University Teaching Hospital (LUTH). West Afr J Med. 1993;12:144-7.

4. Soderstrom RM. Trailing and treating the wandering IUD. Am J Gynecol Health. 1989;3(3-S):33-4.

5. Rafique M. Vesical calculus: a complication of intravesical migration of intrauterine contraceptive device. Int Urogynecol J Pelvic Floor Dysfunct. 2002;13:380-2.

6. Serra I. Appendicitis caused by an intrauterine contraceptive device. Br J Surg. 1986;73:927-8.

7. Timonen H, Kurppa K. IUD perforation leading to obstructive nephropathy necessitating nephrectomy: a rare complication. Adv Contracep. 1987;3:71-5.

8. Zakin D, Stern WZ, Rosenblatt R. Complete and partial uterine perforation and embedding following insertion of intrauterine devices. Diagnostic methods, prevention, and management. Obstet Gynecol Surv. 1987;36:401-17.

9. Adoni A, Ben Chetrit A. The management of intrauterine devices following uterine perforation. Contraception. 1991;43(1):77-81.

10. Otolorin EO, Management of the lost IUD. African J Med Medical Scien. 1985;14(3-4):125-9.

Cite this article as: Devassy $\mathrm{R}$, Gopalakrishnan S, Torres-de la Roche LA, Verhoeven H, De Wilde MS, De Wilde RL. The missing intrauterine device. Int J Reprod Contracept Obstet Gynecol 2016;5:3587-9. 